\title{
Trauma and its Ramifications in Vietnamese Victims of Piracy
}

Stuart Kleinman, MD

New York University Medical Center

Follow this and additional works at: https://jdc.jefferson.edu/jeffjpsychiatry

Part of the Psychiatry Commons

Let us know how access to this document benefits you

\section{Recommended Citation}

Kleinman, MD, Stuart (1987) "Trauma and its Ramifications in Vietnamese Victims of Piracy," Jefferson Journal of Psychiatry. Vol. 5 : Iss. 2 , Article 4.

DOI: https://doi.org/10.29046/JJP.005.2.001

Available at: https://jdc.jefferson.edu/jeffjpsychiatry/vol5/iss2/4

This Article is brought to you for free and open access by the Jefferson Digital Commons. The Jefferson Digital Commons is a service of Thomas Jefferson University's Center for Teaching and Learning (CTL). The Commons is a showcase for Jefferson books and journals, peer-reviewed scholarly publications, unique historical collections from the University archives, and teaching tools. The Jefferson Digital Commons allows researchers and interested readers anywhere in the world to learn about and keep up to date with Jefferson scholarship. This article has been accepted for inclusion in Jefferson Journal of Psychiatry by an authorized administrator of the Jefferson Digital Commons. For more information, please contact: JeffersonDigitalCommons@jefferson.edu. 


\title{
Trauma and its Ramifications in Vietnamese Victims of Piracy
}

\author{
Stuart Kleinman, M.D.
}

Approximately 400,000 Vietnamese fled by boat from their homeland to the United States during the years 1975 to 1985. Many of these people were brutally attacked by pirates during their sojourn. This paper is a preliminary investigation of various ramifications of this trauma in seven Vietnamese "boat people."

We found significant psychopathology which is temporally related to the pirate attacks in two of those interviewed and a prominent absence of survivor guilt in all of those interviewed. Factors such as mastery of previous trauma, advanced knowledge of potential traumata, empowerment fantasies, religious beliefs, and altruistic actions may have helped people to cope successfully during the pirate attacks. Re-telling of their story to others, religious sentiments, contact with other victims of these attacks and a strong future orientation may help people cope with their distress subsequent to the attacks.

Recently there has been an increased appreciation of the role of trauma in the production of psychiatric disturbance. This study investigates a significantly understudied trauma; pirate attack upon Vietnamese refugees during their flight by boat from Vietnam. Four aspects of this experience are explored: the psychological sequelae of the attack, the similarities of these sequelae to those present in other victim populations, the factors which may be helpful in alleviating the distress of these victims, and the factors which may diminish or protect against the development of such sequaelae in victims of terroristic violence.

Trauma produces a unique, reproducible entity characterized by the phases of outcry, denial, intrusion and resolution which is modified by the personality of the subject $(1,2)$. Horowitz proposed an information processing model of stress response in which the phases of intrusion and denial alternate until the discrepancy between internal and external schemata is resolved. The motivating force behind the revision process is the anxiety generated by the mismatch of schemata. Krystal's (3) finding that difficulties with aggression and survivor guilt accounted for much of the psychopathology he observed in concentration camp survivors further contributed to the understanding of

Dr. Kleinman is currently a fellow in the Department of Forensic Psychiatry of New York University Medical Center. This article was written during his third and fourth years of residency at The Institute of Pennsylvania Hospital. 
trauma. Survivor guilt was present in ninety-two percent of the concentration camp survivors studied by Krystal and Niederland. They believed that the survivors' depressive and anxiety reactions emanated largely from overwhelming feelings of survivor guilt (4).

Survivor guilt, which is described as a form of pathological mourning, is closely linked with aggression. Powerful aggressive impulses were unleashed in reaction to the persecution which these people experienced. The conscious experience of this raw aggression was often too anxiety provoking, forcing the individual to employ various means to detoxify these feelings. Often these aggressive feelings were maladaptively handled by such measures as the turning of the aggression against the self, which contributed to the development of depressive projection, which contributed to the production of paranoia; and somatization, which contributed to the chronic headaches and fatigue which many of these survivors experience (4). For those in the camps, the incredible transformation of fantasy into reality magnified the already unfathomable events into a virtually unprocessable stress experience, often resulting in severe psychopathology (5).

Lifton, in his work with survivors of Hiroshima, contributed to the understanding of how individuals actually cope when they are in the midst of the unfathomable. He created the term psychic closing off to describe how individuals remain cognitively aware but emotionally blind to the same situation. They are able to do so using a combination of denial and isolation of affect. Psychic closing off, which is adaptive during the traumatic event, becomes illness when it continues to be used after the event. It may lead to withdrawal or in its most extreme form to what has been described as the Musulman or living dead condition $(6,7)$. Adaptation also became illness in a number of survivors of the camps who survived, in part, as a result of their hypervigilance. This same hypervigilance in the context of life outside of the camps led to emotional distress and the label of paranoid illness (7).

A number of studies have detailed the phenomena found in survivors of violent attack. Symonds classified the stress responses he observed in a population of victims of violent crime into four phases: denial, reality, traumatic depression and self-recrimination, and resolution and integration (8). He suggests that the stress operative in these victims of violence emanates largely from the hostile manner in which they are often treated by society. This "secondary victimization" generates distressing, sometimes overwhelming, feelings of isolation and helplessness which Karen Horney termed basic anxiety (9). Another victim group, Cambodian concentration camp survivors, were found to suffer from post-traumatic stress disorder thus providing support for the cross cultural validity of this diagnosis $(10,11)$. Children of Chowchilla, California who were kidnapped were found upon four year follow-up to experience, among other symptoms, a sense of profound embarrassment for having been so vulnerable (a feeling also found in Cambodian concentration camp survivors (10)) a sense of having a foreshortened future, psychophysiological reenactment of the physical 
disturbances and sensations they had experienced during the kidnapping, and the phenomenon of death dreams (12). During the kidnapping itself a number of the children experienced a distortion of time, a sensation also present in a group of prison guards studied by Hillman who were taken hostage by inmates during a riot in a New Mexico prison. Many of these hostages recalled being gripped by an existential fear of death, a sense that death was truly imminent, during the incident (13).

The sequelae of such traumata may endure for long periods of time. Nazi concentration camp survivors (3), Japanese-held Australian (14) and German and Japanese-held American prisoners of war (15), continue to experience depression or post-traumatic stress disorder four decades after their internment.

Measures which may help people cope during these traumatic incidents include religious thinking and behavior and caring for other hostages. These were found by Soskis to be helpful for a group of Israeli hostages held by Palestinian terrorists (16). Religious thinking was also helpful for the previously mentioned New Mexico prison guards (13). Moreover, Soskis found that six years after the terrorist incident the major coping mechanisms employed by the former hostages were religious thinking and behavior and helping and sharing with other former hostages (16).

Violence may influence the development of psychopathology in many ways. Bastiaans, who studied South Moluccan terrorism in the Netherlands, found that "the more negative experiences the hostages had gone through and the more frightened they had felt, the more negative effects they manifested" (17) and Hillman concluded that it was the intensity of the experience, not the duration that most strongly affected the hostages (13). Hillman also felt that no amount of preparation can adequately anticipate the hostage experience. Krystal adds the important point that the degree to which an event is traumatic depends greatly on the manner in which the individual perceives the event (3). The issue of individual perception reinforces the concept that the subsequent development of psychopathology always bears an individual imprint.

The study of Vietnamese victims requires a familiarity with Vietnamese psychology. The Vietnamese conceptualize health as a state in which an individual's life forces are balanced and symmetrical. Disruption of this balance results in illness, mental or physical. Psychotherapy as it is practiced in the West is virtually non-existent. In the Asian tradition of tolerance and non-confrontation, most individuals are left to the care of the family. Only when an individual is dien, "seriously crazy," and unmanageable to the point at which he can not be controlled by the family, is he brought to a psychiatric hospital for treatment.

Depression, which is common in victims of significant trauma, primarily presents in the Vietnamese in the form of somatic complaints such as headaches or fatigue. Feelings of depression are either rarely expressed or experienced in a different way (Merkel L: Controversies in the study of Asian refugee mental health. Presented at the Mid-Atlantic Region Association for Asian Studies 
annual meeting, 1986). Anxiety, of which post traumatic-stress disorder is a form, was never mentioned by those interviewed by Merkel. People complained of "thinking too much" but did not elaborate beyond (Merkel L: Background: the medical system in Vietnam in Refugee Mental Health. Philadelphia, The Nationalities Service Center, 1985).

\section{THE BOAT PEOPLE}

During 1975, 125,000 Vietnamese managed to flee to the United States and during the next ten years this number swelled to a total of approximately 400,000 Vietnamese (18). These people, labeled by the media as "boat people" because of the crude, flimsy boats which were often their mode of exodus, began streaming out of Vietnam after the fall of Saigon to the North Vietnamese Army in 1975. The number of people attacked during this sojourn is unknown. However, it is known, for example, that of the 35,462 boat people who reportedly left Vietnam during the years 1981-1986 destined for Thailand, 733 were killed by the pirates, 1050 were raped, 655 were abducted, and 1,323 are missing. These figures are probably gross underestimations (The United Nations High Comissioner for Refugees). The large number of people involved accentuates the importance of efforts directed at understanding the distress of this group.

The pirates whom the "boat people" encountered were of various national origins, including Thai, Malaysian and Indonesian and were described as being of two types, professional and non-professional. The non-professional or "good" pirates forcibly took money and other valuables in exchange for directions to the nearest land mass, occasionally a tow in that direction or food and water. The professional or "bad" pirates, who could often be identified by their vessel's absent or blacked out "license plate," did not engage in barter. Utilizing superior arms and manpower, they stole whatever valuables they could find, often beating, raping, killing or throwing people overboard in the process. Occasionally they would ram and sink their looted victim's boat.

\section{METHOD}

Subjects consisted of seven Vietnamese individuals (two of whom were married), who had journeyed out of Vietnam with the goal of eventual patriation in the United States and who were attacked by pirates during their sojourn. They were interviewed using a semi-structured instrument that was designed specifically for this project. Two of the interviews were conducted in English by the author and the remainder were conducted in Vietnamese with the translation performed by either a Vietnamese social worker (M.S.W.), herself a "boat person," or a Vietnamese surgeon, also a "boat person." Careful consideration was given to the attempt to avoid creating an interview environment which was in itself another trauma. 
The subjects were selected through three sources. They were recruited either from members of the local Philadelphia Vietnamese community whom the interviewer had encountered at area Vietnamese restaurants, from the caseload at the Nationality Service Center of Philadelphia, or from the caseload of the Camden County Department of Health. All who participated were volunteers who were informed of the nature of the research project.

\section{RESULTS}

Two of the subjects interviewed demonstrated severe psychopathology which showed a clear temporal relationship to the stressor experience, pirate attack. One individual exhibited mild psychopathology and the remaining four demonstrated no evidence of psychopathology. Subject number five, who was so overwhelmed by the sight of the pirates that he jumped overboard, suffers from the following: hypervigilance, startle reactions, nightly dreams of pirate attacks or of being in a re-education camp, intrusive thoughts of pirate attacks or of being in a re-education camp, a phobia of the ocean, feelings of confusion when thinking of the pirate attack, emotional numbness, feeling a "little depressed," a "heavy heart," shame for his behavior on the boat, constant preoccupation with the future, and partial amnesia of the pirate attack and the journey. This man left Vietnam four years ago and his symptoms, which his wife corroborates, are becoming progressively worse. When offered treatment upon the conclusion of the interview he refused, stating he did not want "hot medicine" (In Vietnam, Western medicine is often considered to be "hot" while Eastern medicine is considered to be "cold") for fear it would counteract the "cold medicine" he was receiving from a Chinese doctor for his arthritis.

Since his arrival in the United States, subject number six, who as captain of his boat was severely beaten by the pirates, complains of having an "inferiority complex" consisting of feelings of shame for his perceived cowardice during the pirate attack and of the belief that he is not as "good" as others. Additionally he described being tormented by guilty thoughts concerning his sexual trespasses in Vietnam, which were not consistent with his Catholic creed, concerning his not having been "strong" enough to always tell the truth to his friends in Vietnam and concerning the manner in which he had treated his father; they had been on the verge of blows prior to his departure. These intrusive thoughts are most prominent during the night when they lead him to fear that he is "going crazy." Concomitant with the thought that he is inferior is the grandiose fantasy that he is a better problem solver than the other Vietnamese in his southern New Jersey community. Additionally, he complains of initial insomnia, which coincides with the periods when the intrusive thoughts are most distressing, a feeling of isolation, memory lapses, and the fear that one day he might unintentionally kill another person or himself. He demonstrates no signs of psychosis and strongly pleaded for treatment.

A comparison of the psychologic phenomena experienced during the 
pirate attacks by the Vietnamese with those experienced by the victim groups earlier discussed is found in Table One.

TABLE 1.

Psychologic Phenomena Operative in the "Boat People"

\begin{tabular}{ll}
\hline \multicolumn{1}{c}{ Phenomenon } & Subject Number \\
\hline Existential fear of death during the attack & $1,2,3,5,6,7$ \\
Distortion of time during the attack & $3,4,6,7$ \\
Feelings of isolation during the attack & $3,4,5,6$ \\
Feelings of powerless or helplessness during the attack & $3,5,6$ \\
Survivor guilt & 0 \\
Feelings of pride regarding the attack & $1,4,7$ \\
Feelings of shame or humiliation regarding the attack & 5,6 \\
Death dreams after the attack & 0 \\
\hline
\end{tabular}

Various measures have helped these people to cope with their victimization experience. These measures include maintaining contact with other survivors of the attacks, retelling their story to others, religious beliefs, preoccupation and identification with the future success of their progeny, suppression of all thoughts relating to their experience, e.g. "it's in the past," and the research interview itself. Prior to his interview subject number six slept for five hours, the most he had slept for a week, and on the day of our interview was able to recollect much of what he believed he had forgotten and was significantly less disturbed by his "inferiority complex." He voiced the hope that the "doctor" (a figure who in Vietnam is imbued with great respect and authority) would forgive him for his "cowardice" during the pirate attack (he had thrown his browning pistol overboard and submitted to a severe beating at gunpoint by the pirates). Subject number three "enjoyed" talking "to someone who understands and cares for my people" and subjects four and seven were, at least temporarily, narcissistically gratified by their opportunity to tell of the ways in which they had managed to survive their pirate attacks.

Another example of a coping aid, religion, has been helpful for at least one subject who attends church each Sunday. She does not particularly believe in God but while she is present in the church she recaptures the peacefulness which her prayers had helped bring her during the attack. None of these people had utilized or considered utilizing psychotherapy as a coping aid. Table Two indicates the distribution of these coping aids.

Certain factors that were present in those who suffered no apparent sequelae were absent or present in a qualitatively different way in those who suffered from significant sequelae. These factors may have diminished or protected against the development of serious later emotional problems. Strong adherence to a religious belief system was one such factor. One woman, who earlier had fled from the north to the relative safety of the south after the French defeat, attributed her survival during this trek to an icon of the Virgin 
TABLE 2.

Coping Mechanisms

\begin{tabular}{ll}
\hline \multicolumn{1}{c}{ Mechanism } & Subject Number \\
\hline Contact with other survivors & 1 \\
Re-telling of the trauma story & 4,7 \\
Religious belief & $2,3,5$ \\
Preoccupation with progeny's future & 2,4 \\
Thought suppression & $1,2,3,4,5,6,7$ \\
Research interview & $3,6,7$ \\
\hline
\end{tabular}

Mary which she had carried with her. On her journey out of Vietnam she brought this icon with her in the belief that it had been blessed by God and would help insure her survival. As she had hoped, and perhaps because she had hoped, this icon greatly soothed her during the journey and helped her face the pirate attack with less fear.

Another factor which seemed to be important was that of having successfully mastered a previous trauma experience. Prior to his departure from Vietnam subject number seven, as a result of his successful escape from a re-education camp and his subsequent success in eluding recapture, felt "confident" in his ability to deal with the pirates. He did not develop significant emotional difficulties after his experience with the Vietnamese army and police and also failed to develop emotional difficulties after having been attacked by pirates. Conversely, subject number five, who had spent time in a re-education camp, never fully reconciled himself to the massive humiliation he had suffered. The pirate attack evoked memories of this prior trauma. Simply the sight of the pirates provoked such horror in him that he jumped overboard and now, four years later, he continues to be haunted by this experience.

Subject number six provides a more complex example of the influence of previous trauma. He had experienced both successes and failures in his dealings with his North Vietnamese masters. He had managed to escape a re-education camp after only three days of imprisonment and had managed to dodge the police for many months afterward. These experiences left him feeling "strong." Later he was captured and imprisoned for twenty months. During this time he was immobilized by leg irons and often beaten on the chest. When he was attacked by pirates the first two times, he coped quite well, functioning in the role of leader and bargaining effectively with them. He recalls that as the third group of pirates approached, he became obsessed (for unclear reasons) with the notion that these pirates would put him in leg irons and beat him on the chest. Since this third pirate attack (in which his fears became reality as he was once again beaten on the chest), he has suffered from a worsening "inferiority complex."

A related factor which may have been protective was prior knowledge of the various risks entailed by the journey. There was a hierarchy in terms of the protective effect of advance knowledge. The closer to the actual experience of 
being attacked the informant was, e.g. having actually been attacked versus having heard rumors of attacks, the more effective protection this information seemed to provide. Paradoxically, in the one instance in which advanced knowledge was not protective (subject number five), it served to intensify the difficulty of coping with the pirate attack.

Altruistic actions on the behalf of other members on the boat also seem to have been protective. Subject number four, who did not develop subsequent psychopathology, volunteered to assume the dangerous position of captain and to attempt to negotiate with the pirates.

Physiologic sensations were also possibly protective. Subject number seven recalled feeling petrified as he watched a pirate brandish a knife over the head of a fellow boat member. His horror dramatically vanished when he suddenly sighted a bucket of water located between he and his captors. Instead his attention became anchored to the bucket of water and his insatiable thirst. Impulsively he ran from his guards and dove for the bucket of water blind to the danger of his actions. Why he noticed the bucket at that particular moment during the attack is an unanswered question. Nevertheless, his thirst functioned to shield him from full awareness of the terror of his situation.

None of the victims were able to utilize soothing fantasies to counter their horror during the attacks as they all reported being too transfixed with fright to be able to shift their attention elsewhere. Fantasy was, however, used before and after the attacks. Subject number six had the fantasy that his browning pistol, a very modest weapon in comparison with those of the pirates, would actually provide him with sufficient power to fend off whatever type of attack he might encounter. He also fantasized, with little basis in reality, that any attack on his boat would be successfully repelled by the young men on the craft who would rally together in a sense of blissful camaraderie to defend the group. Subject number three, who had never fought or dreamed herself capable of fighting, developed the fantasy after the fourth pirate attack that she would successfully defend her family against any further attack by striking the pirates on the head with "a piece of wood." This fantasy, she recalls, helped to modulate her tremendous terror.

Humor and solacing imagery were also not helpful. Again it was reported

TABLE 3.

Protective Factors

\begin{tabular}{ll}
\hline \multicolumn{1}{c}{ Protective Factor } & Subject Number \\
\hline Advanced knowledge of trauma & $1,2,3,4,5,6,7$ \\
Mastery of previous trauma experience & $1,2,3,4,6,7$ \\
Altruistic actions & $1,3,4,6,7$ \\
Strong religious belief during the attack & $2,3,4$ \\
Overwhelming physiologic sensations & $1,3,7$ \\
Empowerment fantasy(s) & $3,6,7$ \\
\hline
\end{tabular}


that these people were too frightened to think amusing thoughts or to create solacing or distracting images. Table Three indicates the distribution of these protective factors among the study population.

\section{DISCUSSION}

Several aspects of the piracy experience have been examined. These include the subsequent psychopathology, the comparison of this group's experience with that of other victim groups, the identification of factors which aid in alleviating the resultant emotional distress, and the elucidation of factors which may diminish or protect against the development of subsequent psychopathology.

In terms of subsequent psychopathology, subject number five suffers from what the DSM-III describes as post-traumatic stress disorder (PTSD). He and his wife both state that he was without symptoms of an emotional disorder prior to having been attacked by pirates. Since the attack, however, he has suffered from progressively worsening symptoms of PTSD. Neither he nor any of the other subjects experienced head injury during or starvation before or after the attack; two factors that can produce symptoms similar to those found in PTSD (1). Subject number six has developed a constellation of symptoms which neither fully meet the DSM-III criteria for major depression nor PTSD but are clearly related temporally to the pirate experience. His symptoms are particularly interesting as their form, intrusive thoughts, is consistent with PTSD but their content, memories of events which occurred prior to his leaving Vietnam, is not of the traumatic event which probably caused his present distress, the brutal beating and humiliation he received from the pirates. As has been described, before departing Vietnam he felt quite guilty for his sexual indiscretions, the lies he had told his friends, and particularly for the anger he had felt toward his father. The beating he received from the pirates may have been interpreted by him as just punishment for both his actual and perhaps (unconsciously) wished for misdeeds. Reality thus reinforced in a dramatic way his pre-existing belief that he was a "bad" person. Since this attack he complains of having an "inferiority complex" with its associated intrusive thoughts.

Additionally, this man has developed the belief that he is a better problem solver than the other Vietnamese in his community. This belief may originate in what he perceives as his failure as ship's captain to perform his duty to protect those in his charge. He describes feeling ashamed and humiliated for his "weakness" during the pirate attack. Possibly as a reaction to these painful feelings he defensively has created the idea that he is a quite clever problem solver, not at all the person who failed to solve the problem of how to protect his comrades.

Most striking in the comparison of the "boat people" to other victims of violent attack is the "boat people's" lack of survivor guilt. Why this is so is not clear. Many of the survivors feel that their family members who did not or have 
not made it out of Vietnam are "happy" for their success. Furthermore those who are Buddhist believe that by having contributed to their survival the family members earned "merit" and will be rewarded by a better rebirth. Thus the survivors feel that there is no reason to be distressed for having survived while others did not. The family not the individual is of greatest importance in Vietnam. Traditionally, the core identity of the Vietnamese is much more strongly linked to the family unit than to the individual. If one family member survives, it is as if the entire family has survived and is perceived as a victory for the family. As one of the survivors expressed, "I feel sad for my brother having died, but I don't feel bad for having made it." These people may have felt ashamed for the way they conducted themselves during the attack but not for the fact of having survived the attack.

A related phenomenon is the sense of pride that many of the survivors feel for having successfully negotiated their ordeal. There was an almost grandiose manner to the way in which many of these people discussed their journey. This grandiosity may in part serve a defensive function, but it is also primary in the sense that survival is viewed as a "victory" in the struggle against oppressive forces such as the pirates and thus merits a feeling of pride. Furthermore, the Vietnamese conceive of life as being essentially bad, and the ability to survive without committing shameful acts indicates a person is "strong" and demonstrates "good blood" or family. That in this culture it is appropriate to feel proud for having survived illuminates further the virtual lack of guilt associated with survival.

Various means have been employed to cope with this trauma. Those with severe psychopathology obviously have not been able to cope successfully with what they experienced. Subject number six, who suffers from severe psychopathology, did seem to respond, at least temporarily, to the transference expectations of being interviewed by a doctor. Sharing of their experience with others, participation in religious activities and a strong future orientation consisting of an intense focus on the future of their progeny, have helped several of the survivors. None of the subjects had participated or were interested in, consistent with their cultural heritage, psychotherapy. Several, however, were helped by the repetitive recounting of their "story" to others. The constant re-telling of their story may have provided the opportunity to re-live, to re-work and ultimately to integrate their experience, much of what psychotherapy also attempts to accomplish. Perhaps the safety provided by a trusted member of the same cultural group created an environment which facilitated the discussion of this material, an environment which might be more difficult for a Western psychotherapist to provide. Despite the fact that recollection may have been helpful to some, thought suppression and avoidance were employed at times by every subject and for the majority of subjects were utilized more commonly than conscious recollection.

Various factors may have prevented or diminished the development of psychopathology after the pirate attacks. The mastery of previous trauma, 
especially if the trauma were in some way symbolically related to the experience of pirate attack, seemed to innoculate against the development of psychopathology or to diminish the psychopathology which did develop. Advance knowledge of the possibility and types of pirate attacks also appear to have been protective. This knowledge provided the opportunity to experience vicariously the future trauma and to begin to process and master it under conditions far more conducive to the integrative process than the actual attack. Such vicarious experiencing may be similar to the preparatory mourning that is done prior to the anticipated death of a loved one. The in-vitro mastery of trauma may provide a protective effect similar to that produced by the in-vivo mastery of trauma. The exception to the protective effect of advance knowledge, subject five, developed such great anxiety upon receiving this knowledge, possibly due to his having failed to master the previous trauma of the re-education camp, that it interfered with his ability to process this information.

Altruistic actions also may have had a protective effect. This type of behavior both diminishes isolation as such actions are directed towards another person and decreases feelings of powerlessness and helplessness as such actions momentarily impart a sense of accomplishment and empowerment. If basic anxiety is a pathogenic force, then it is conceivable that the reduction of these feelings by altruistic behavior would be protective. The victims of the hydrogen bomb, who were severely hindered in their attempts to aid their companions, provide a further illustration of this hypothesis. The contamination of Hiroshima's water supply (water is a powerful symbol of life for the Japanese) (6) prohibited the survivors from even quenching the thirst of their dying brethren. Perhaps if they had been able to do so, some measure of their subsequent suffering would have been mitigated. Additionally, altruistic actions may help to prophylax, in certain individuals, against the later development of shame, an affect to which the Vietnamese are particularly sensitized.

Strong religious belief accompanied by faith in an omnipotent force or being may have been protective for a similar reason. By allying oneself with a greater power, one may feel as if he has acquired a share of that power and is, at least momentarily, not the helpless, powerless being that reality shows him to be. Fantasies which engendered the fantasizer with a sense of power may also have been helpful for the same reason.

\section{CONCLUSION}

The "boat people" represent a large group of people whose psychological needs remain inadequately understood. In order to further the understanding of these people, future studies incorporating larger sample sizes, follow-up interviews, and the provision of controls for the myriad of variables involved in this experience are necessary.

Whether this preliminary study is applicable to those Vietnamese who choose not to be interviewed, as well as other groups, and thus to a more general 
understanding of stress response syndromes is a question that merits further study. If those factors which seemed to provide protection against the subsequent development of psychopathology in the "boat people" are found to offer protection for other victim groups as well, then the implementation of such protective factors in the training of individuals who face the prospect of future violent assault may help to diminish the psychological sequelae of such trauma. Ultimately the aim of this work is to acquire the understanding that will be useful in the treatment of the "boat people" and other groups of victims and will aid in the creation of techniques which can prevent the development of such sequelae in those who may be victims in the future.

\section{REFERENCES}

1. Horowitz M: Stress Response Syndromes. New York, Jason Aronson, 1976

2. Horowitz M: Disasters and psychological responses to stress. Psychiatric Annals $15: 161-167,1985$

3. Krystal H (ed): Massive Psychic Trauma. New York, International Universities Press, 1968

4. Krystal H, Niederland WG: Clinical observations on the survivor, in Massive Psychic Trauma, Edited by Krystal H. New York, International Universities Press, 1968

5. Niederland WG: The psychiatric evaluation of Emotional disorder in survivors of Nazi persecution, in Massive Psychic Trauma. Edited by Krystal H. New York, International Universities Press, 1968

6. Lifton R: Observation of Hiroshima survivors, in Massive Psychic Trauma. Edited by Krystal H. New York, International Universities Press, 1968

7. Niederland WG: An interpretation of the psychological stresses in concentrationcamp life and the late after effects, in Massive Psychic Trauma. Edited by Krystal H. New York, International Universities Press, 1968

8. Symonds M: Victimization and rehabilitative treatment, in Terrorism. Edited by Eichelman B, Soskis D, Reid W. Washington, D.C., American Psychiatric Association, 1983

9. Symonds M: Victims of violence: psychological effects and aftereffects. Am J Psychoanal 35:19-26, 1975

10. Kinzie JD, Fredickson RH, Ben R et al: Posttraumatic stress disorder among survivors of Cambodian concentration camps. Am J Psychiatry 141:645-650, 1984

11. Boehnlein J, Kinzie D, Ben R et al: One year follow-up study of posttraumatic stress disorder among survivors of Cambodian concentration camps. Am J Psychiatry 142:956-959, 1985

12. Terr C: Chowchilla revisited: the effects of psychic trauma four years after a school-bus kidnapping. Am J Psychiatry 140:1543-1550, 1980

13. Hillman RG: The psychopathology of being held hostage. Am J Psychiatry 138:1 1931197,1981

14. Tennant C, Goulston K, Dent O: The psychological effects of being a prisoner of war: forty years after release. Am J Psychiatry 143:618-621, 1986

15. Kluznick J, Speed N, VanValkenburg C, Magraw G: Forty year followup of United States Prisoners of War. Am J Psychiatry 143:1443-1446, 1986 
16. Soskis D, Ayalon O: A six-year follow-up of hostage victims. Terrorism 7:411-415, 1985

17. Bastiaans J: Consequences of modern terrorism, in Handbook of Stress Theoretical and Clinical Aspects. Edited by Goldberger L, Breznitz. New York, The Free Press, 1982

18. From Saigon to San Diego, in The Economist. London, April 27, 1985 